\author{
Dr. sc. Miodrag Mićović, redovni profesor \\ Pravnog fakulteta Univerziteta u Kragujevcu
}

\title{
FINANSIRANJE SPORTA I SPONZORSTVO
}

\author{
UDK: 336 : 796/799 \\ Primljeno: 20. 01. 2019. \\ Izvorni znanstveni rad
}

\begin{abstract}
Sponzorstvo, posebno kada se radi o profesionalnom sportu, ima naročit značaj za finansiranje te vrste sportskih aktivnosti. Razlog tome je što se uz pomoć sponzorstva na efikasan način zadovoljavaju interesi sponzora da se kroz povezivanje sa nosiocem nekog sportskog sadržaja maksimalno poveća njegova prisutnost i prepoznatljivost u javnosti. Istovremeno, zahvaljujući sponzorstvu, sponzorisani stiče mogućnost da postiže bolje i prestižnije rezultate u odnosu na druge. S obzirom da sponzorstvo ima svoje specifičnosti, koje ga jasno odvajaju od drugih ugovornih odnosa, u radu je najpre određen pojam sportskog sponzorstva, a potom je ukazano na značaj imidža sponzorisanog i pravo korišćenja imidža, koje zaključenjem ugovora stiče sponzor, na odnos između individualnog i kolektivnog imidža, i na kraju na ograničenja u pogledu mogućnosti zasnivanja i realizacije sponzorstva.
\end{abstract}

Ključne reči: sport, ugovor, sponzorstvo, sponzor, imidž, odnos

\section{UVODNE NAPOMENE}

Odvijanje sportskih aktivnosti je moguće samo ako su obezbeđeni neophodni izvori finansiranja. U osnovi, sredstva potrebna za finansiranje amaterskog i vrhunskog sporta obezbeđuje država (s jedne strane, ulaganjem u sport nastoji se da se osigura dobro zdravstveno stanje nacije, a, s druge strane, da se na najefikasniji način promoviše država, njena politika i vrednosti), ${ }^{1}$ a kada se radi o profesionalnom sportu sredstva se obezbeđuju, pre svega, iz privatnih izvora finansiranja, pri čemu sponzorstvo $^{2}$ predstavlja jedan od najznačajnijih načina finansiranja sportskih

1 Sredstva koja se ulažu u sport iz godine u godinu rastu, jer se pokazalo da je to najbolji i najefikasniji način za državu da ostvari željene rezultate u pogledu mentalnog i fizičkog stanja nacije. U Francuskoj, na primer, država je u 2017. godini izdvojila za potrebe sporta 36,9 milijardi evra. O tome: http://www.injep. fr/article/le-poids-economique-du-sport-edition-2017-11631.html.

2 Ideja o pružanju pomoći iz komercijalnih razloga počela je da se razvija sredinom XIX veka. Među prvim sponzorskim ugovorima pominje se ugovor koji je kompanija Spiers and Pond 1861. godine zaključila povodom turneje britanskog kriket tima po Australiji, u vrednosti od 11000 funti sterlinga. U Francuskoj prvi ugovor o sportskom sponzorstvu zaključio je Michelin 1881. godine, a radilo se o pružanju materijalne podrške biciklistima kroz snabdevanje baciklističkim gumama. 1896. godine Kodak i Coca Cola zaključili su prvi ugovor o sponzorisanju sportskog događaja - Olimpijskih igara u Atini. Prvi ugovor o sponzorstvu kroz preuzimanje imena sponzora zaključen je 1904. godine između Bayer-a i fudbalskog kluba iz Leverkuzena, koji od tada pa do danas nosi naziv Bayer Leverkuzen. O tome: Dubé Kimberley, D., Le sponsoring sportif: un marketing gagnant pour les entreprises face à la crise ? Lyon, 2013, https://ecole-de-commerce-de-lyon.fr/wp-content/ uploads / 2015/07/M\%C3\%A9moireMarketing-Kimberley-D-M1-.pdf, str. 11. 
aktivnosti, ${ }^{3} \mathrm{i}$ to zbog dva međusobno povezana razloga. Prvo, oni koji daju sredstva imaju interes da kroz povezivanje sa nosiocima nekog sportskog sadržaja, koji izazivaju interesovanje javnosti, povećaju vlastitu prisutnost i prepoznatljivost u javnosti. Drugo, oni koji primaju sredstva, stiču mogućnost da postižu bolje i prestižnije rezultate u odnosu na druge. ${ }^{4}$

Sponzorstvo, koje u terminološkom i sadržajnom smislu ima izvorište u engleskom jeziku i anglosaksonskoj praksi, koristi se kao način finansiranja, radi zadovoljenja interesa i sponzora i sponzorisanog, u različitim oblastima društvenog života. ${ }^{5} \mathrm{~S}$ tim u vezi susreće se opšte određenje prema kome je sponzorstvo ugovor kojim se sponzor obavezuje da finansira određene kulturne, sportske, umetničke ili naučne aktivnosti u zamenu za promociju i reklamu svoje robne marke (imena). ${ }^{6}$ Ili, posebnim pravilima se određuje da je sponzorstvo svaki vid finansijske ili druge podrške sponzora drugom pravnom ili fizičkom licu ili njegovim aktivnostima u cilju promocije sponzorovog imena, naziva ili žiga, aktivnosti ili proizvoda (čl. 64. Zakona o oglašavanju). ${ }^{7}$ Međutim, primetno je da o sponzorstvu još uvek ne postoje opšta ugovorna pravila, a nema ni posebnih kojima bi bila uređena pitanja od značaja za sportsko sponzorstvo. ${ }^{8}$ Ugovarači raspolažu sa relativno visokom autonomijom u pogledu uređenja svog odnosa povodom ugovora o sponzorstvu, mada bi razlozi očuvanja regularnosti takmičenja i zaštite sponzora mogli da učine opravdanim donošenje posebnih pravila kojima bi se postavili graničnici u pogledu zasnivanja i dejstva ugovora o sponzorstvu. ${ }^{9}$

U daljim izlaganjima pažnja će biti usmerena na određenje pojma ugovora o sportskom sponzorstvu, osobine i prirodu ovog ugovora, prava i obaveze ugovarača, vrste sportskog sponzorstva, faktore koji ograničavaju mogućnost da se uspostavi sponzorski odnos ili da sponzorski odnos traje.

3 Na osnovu sponzorskih ugovora, fudbalski klubovi obezbeđuju 20\% potrebnih sredstava, 25\% rukometni klubovi, 40\% ragbi i košarkaški klubovi. O tome: Buy, F. i dr., Droit du sport, Paris, 2009, str. 819.

4 O tome: Simon, G. i dr., Droit du sport, Paris, 2012, str. 372.

5 Sponzorska ulaganja se iskazuju u milijardama evra, na godišnjem nivou rastu $10 \%$, a najveći deo je usmeren ka sportu, iz prostog razloga što, na primer, u Francuskoj svaki Francuz ,potroši“ godišnje 76 sati prateći sport. O tome: Burger, G., Interets et enjeux du partenariat entre sportifs de haut niveau amateurs et entreprises, 2010, http:/www.guillaumeburger.fr/blog/public/2010_Mai-Aout/MemoireGB pdf, str. 13

6 http://www.jobintree.com/dictionnaire/definition-sponsoring-1172.html.

7 Sl. glasnik Republike Srbije, br. 6/16.

8 Zakon o sportu Republike Srbije (S1. glasnik RS, br. 10/16) pominje u okvire dve odrednice sponzorstvo: kao jedan od načina za sticanje imovine od strane sportskih udruženja (čl. 70) i kao prepreku da vrhunski sportista dobije novčanu pomoć (čl. 128).

9 O tome: Simon, G. i dr., nav. delo, str. 373. 


\section{POJAM I OSOBENOSTI UGOVORA O SPONZORSTVU}

Od prvih sponzorskih aktivnosti prošlo je više od 100 godina, tokom kojih je sponzorstvo imalo nekoliko razvojnih faza ${ }^{10}$ ali to nije bilo dovoljno da se definiše pojam i pravila sportskog sponzorstva. Razlog tome treba tražiti prvo u tome što sam pojam sponzorstvo ima dvojako značenje: koristi se u smislu dobročinstva, darivanja, mecenata, kao pružanje materijalne podrške korisniku, koji zbog toga nema nikakvu obavezu prema dobročinitelju, i kao pružanje materijalne podrške nekome ili nečemu radi ostvarenja direktne koristi od toga. ${ }^{11}$

Prema savremenoj poslovnoj praksi sponzorstvo se poistovećuje sa drugim značenjem, shodno kome sponzorstvo predstavlja komercijalni odnos između sponzora, koji pruža finansijsku podršku, i sponzorisanog, koji pruža usluge oglašavanja i javnog prezentovanja sponzora (sponzorstvo odlikuje ravnoteža ugovornih obaveza, čega kod mecenata nema). ${ }^{12}$ Osim jezičkog značenja termina sponzorstvo, kao razlog teškoće u definisanju sponzorstva navodi se da se radi o ugovoru sa hiljadu lica, ${ }^{13}$ koji se pojavljuje u raznovrsnim oblicima (kao sponzorstvo jednog sportiste, ekipe, događaja, stadiona). ${ }^{14}$ Otuda i različite kvalifikacije o pravnoj prirodi sponzorstva. ${ }^{15}$ Pojedini autori navode da sponzorstvo ustvari predstavlja poseban način oglašavanja kojim se ostvaruje promocija sponzora, ${ }^{16}$ pri čemu se kao sredstvo podrške (promocije) koristi neki sportski događaj ili poznati sportista. ${ }^{17}$

10 Razlikuju se četiri razvojne etape, pri čemu se za aktuelnu navodi da je karakteriše nastojanje sponzora da iskoristi potencijale sponzorisanog i dopre do ciljne grupe. O tome: https://hr.wikipedia.org/ wiki/Sponzorstvo

11 Za razliku od mecenata, sponzorstvo karakteriše ravnoteža ugovornih obaveza: na ime materijalne podrške koju pruža, sponzor očekuje da ostvari direktnu korist, koja vrednosno odgovara pruženoj podršci, od promovisanja koje vrši sponzorisani. Inače, suprotno mecenatu (nije potreban ugovor), povodom sponzorstva potrebno je da se zaključi ugovor kojim se preciziraju prava i obaveze ugovornih strana. O tome: Les contrats de sponsoring sportif, http:// excerpts.numilog.com/books/9782359711172.pdf, str. 11; Poreski tretman donatorstva i sponzorstva u srbiji, https:/www.poslovnisavetnik.net/poreski-tretmandonatorstva-i-sponzorstva-u-srbiji/

12 O ovome: Simon, G. i dr., nav. delo, str. 372; Les contrats de sponsoring sportif, http:// excerpts. numilog.com/books/9782359711172.pdf, str. $10-12$. 10.

13 Les contrats de sponsoring sportif, http:// excerpts.numilog.com/books/9782359711172.pdf, str.

14 Buy, F. i dr., nav. delo, str. 821; Simon, G. i dr., nav. delo, str. 372.

15 Razlog tome je što sponzorstvo, zamišljeno kao „komunikacijski sistem“, objedinjuje niz prestacija, koje mogu da se različito kvalifikuju. Tako, nošenje opreme sa znakom sponzora može se kvalifikovati kao licenciranje spozorisanog da je uz naknadu nosi radi promovisanja sponzora. Ili, kao iznajmljivanje reklamnog prostora na mestu održavanja sportskog događaja; kao odnos sa elementima najma, u slučaju korišćenja materijala koji je dobijen od sponzora. Kada se ugovor zaključuje između sponzora i sportiste, on bi mogao da se kvalifikuje kao ugovor o delu ili radu. Ova druga kvalifikacija je moguća ako su zadovoljena dva kriterijuma: da se daje naknada za obavljeni rad i da između sponzora i sportiste postoji odnos subordinacije. O tome: Monnerville, F., Le parrainage sportif : aspects contractuels, Legicom, br. 2000/23, str. 87.

16 Shodno odredbama Zakona o oglašavanju i pravilima o tome ko može da bude oglasivač i prenosilac oglasne poruke, sponzorstvo se u pogledu jednog, personalnog, elementa približava oglašavanju, a to je slučaj kada se kao prenosilac oglasne poruke pojavljuje organizator sportskog događaja (čl. 2. st. 1. tač. 4).

17 U skladu sa takvom kvalifikacijom sponzorstvo se određuje kao finansijska ili materijalna podrška koja se pruža nekom sportskom događaju, federaciji, ekipi ili sportisti, od strane oglašivača, u zamenu za 
Međutim, ono što svakako odvaja sponzorstvo od oglašavanja roba i usluga je činjenica da ono ima za cilj promovisanje imidža sponzora korišćenjem potencijala sponzorisanog. ${ }^{18}$ To je razlog što se ne može prihvatiti ni stav da sponzorstvo nije ništa drugo nego ugovor o kupovini prostora za oglašavanje. ${ }^{19} \mathrm{~S}$ obzirom da se sponzorisani obavezuje da pruži različite usluge javnog prezentovanja sponzora, može se reći da sponzorstvo, po svojoj prirodi, predstavlja vrstu ugovora o uslugama (delu). Kako naknada koju prima sponzorisani ne mora da bude izražena u novcu, nego u nekom drugom materijalnom obliku (sponzor organizuje sportski događaj uz učešće sportista sa kojima je stupio u poslovni odnos), izvesni autori ističu da se tada radi o dvostrukom ugovoru o delu (ugovoru sa dva lica). ${ }^{20}$

$\mathrm{Na}$ osnovu napred iznetog moglo bi se reći da ugovor o sponzorstvu spada u kategoriju neimenovanih i dvostrano obavezujućih ugovora. Tim ugovorom se sponzor obavezuje da sponzorisanom - sportskoj ekipi, sportisti, sportskoj manifestaciji ili nekom objektu, pruži dogovoreni oblik materijalne podrške, a sponzorisani da na osnovu sopstvenog imidža pruži sponzoru ugovorene usluge javnog prezentovanja (propagande). ${ }^{21}$

Imidž je svojevrsna roba na kojoj sponzor stiče pravo korišćenja na način i pod uslovima koji se određuju ugovorom. Cilj je da se uz pomoć tuđeg imidža, činjenice da je neko sportsko takmičenje, klub ili sportista opšte poznat i prihvaćen u javnosti, kao i usluga koje će biti pružene, ostvari promocija, ali i održi i ojača konkurentski potencijal sponzora na tržištu. ${ }^{22}$ Radi se o bitnom elementu na osnovu koga se sponzorstvo jasno može odvojiti od drugih ugovora. Ali, i elementu povodom koga se postavlja pitanje da li klub može da prenese pravo korišćenja individualnog imidža sportista na sponzora sa kojim je zaključen ugovor o pravu kolektivnog korišćenja imidža sposrtista. U vezi sa tim se zauzima stav prema kome pravo eksploatacije kolektivnog imidža sportista pripada klubu ${ }^{23}$ jer on nastaje kao rezultat aktivnosti kluba, odnosno federaciji, kada se radi o kolektivnom imidžu

različite vidove vidljivosti i saradnje. O tome: Bathelot, B., Définition: sponsoring sportif, https:// www. definitions-marketing.com/definition/sponsoring-sportif/

18 Razvoj imidža sponzora se projektuje na osnovu činjenice što je neki događaj ili sportista poznat u javnosti. O tome: Les contrats de sponsoring sportif, http:// excerpts.numilog.com/books/9782359711172. pdf, str. 13; Simon, G. i dr., nav. delo, str. 372.

19 Buy, F. i dr., nav. delo, str. 821.

20 Isto, str. 822.

21 Prema definiciji iz Kodeksa o oglašavanju i komercijalnoj komunikaciji Međunarodne trgovinske komore (poglavlje B - značenje termina) sponzorsto se određuje kao komercijalni odnos na osnovu koga sponzor ugovorno pruža finansijsku ili drugu podršku sponzorisanom, na obostranu korist, kako bi se uspostavila veza između sponzorovog imidža, marke ili proizvoda sa nosiocem sponzorisanih prava u zamenu za pravo na promociju unapred određenih koristi. Videti: https://www.arpp.org/wp-content/ uploads/2016/05/code_consolide_pratique_publicite_marketing.pdf.

${ }^{22}$ O imidžu: Jeannot-Pagès, Gh., L'image du sportif en droit français, Legicom, br. 2000/23, str. 107112; Grgić, D., Imidž poduzeća i njegov utjecaj na stvaranje konkurentskih prednosti uslužnog poduzeća, Ekonomski pregled, br. 58/2007, str. 586-598.

23 Pravo korišćenja kolektivnog imidža sportista (ekipe) osigurava se zaključenjem ugovora o radu sa sportistima i uz pomoć internih pravila kojima se reguliše položaj sportista. O tome: Monnerville, F., nav. članak, str. 85. 
kluba, vezano za sportske aktivnosti koje sprovodi sportska federacija. Međutim, korišćenje imena ili ugleda sportiste, bez njegovog odobrenja, u komercijalne svrhe a ne informativne, povlači odgovornost za štetu koju trpi sportista zbog povrede ličnog prava ili prava na privatnost. ${ }^{24}$

Povodom raspodele prava na korišćenje imidža u Francuskoj je od strane Nacionalnog centra za vrhunski sport zauzet sledeći stav: pravo eksploatacije pripada organizatoru događaja koji može da sklopi bilo koji sporazum sa ovlašćenim partnerom; sportist ima individualno pravo na svoj imidž; sportista ne može da zaključi bilo koji ugovor koji je u suprotnosti sa pravom sportske grupe (kluba) ili federacije na kolektivni imidž ekipe; ugovori o partnerstvu koje je organizator sklopio ne mogu da kompromituju individualna prava sportista i kolektivna prava ekipa; konačno, obim prava i obaveza svakog može da bude preciziran sporazumom koji se zaključuje sa organizatorom..$^{25}$

U pogledu zaključenja i izvršenja ugovora o sponzorstvu primenjuju se opšta pravila ugovornog prava. To znači da će se smatrati da je ugovor zaključen tek kada se postigne sporazum o bitnim elementima ugovora, $\mathrm{s}$ tim što punovažnost ugovora ne može da bude dovedena u pitanje zbog nesaglasnosti sa sportskom regulativom. ${ }^{26}$ Pri tome, treba imati u vidu da status sponzora ne mogu da steknu lica obuhvaćena pravilima iz Zakona o oglašavanju. ${ }^{27}$

Ukoliko se u ugovor unese klauzula ekskluzivnosti, tada sponzorisani ne može da zaključi ugovor o sponzorstvu sa nekim trećim licem. ${ }^{28} \mathrm{U}$ načelu, sponzori čije aktivnosti ne spadaju u krug sportskih ne zahtevaju unos ovakve klauzule u ugovor. Oni koji uspostavljaju tehničku saradnju sa nekom ekipom, po pravilu, zahtevaju da se u ugovor unese ovakva klauzula zajedno sa klauzulom tajnosti, radi zaštite tehničkog progresa koji su postigli. ${ }^{29}$ Takve klauzule same po sebi nisu nezakonite, ali mogu da postanu ako imaju za predmet ili efekat ograničenje konkurencije na tržištu, ako isključuju samostalnost sponzorisanog u pogledu definisanja i vođenja poslovne strategije. ${ }^{30}$ Kada sportske aktivnosti ili događaj nalažu potrebu postojanja više od jednog sponzora, ugovorom moraju da se jasno odrede prava, ograničenja i odgovarajuće obaveze svakog sponzora. Sponzorisani mora da obavesti svakog od potencijalnih sponzora o svakom od sponzora sa kojima je već zaključio ugovor. Ne može da zaključi ugovor sa novim sponzoroma a da prethodno nije osigurao da to neće narušiti prava postojećih sponzora i, ako je potrebno, bez obaveštavanja postojećih sponzora (čl. B11. Kodeksa o oglašavanju i komercijalnoj komunikaciji

24 Isto, str. 86.

25 Isto, str. 87.

26 Buy, F. i dr., nav. delo, str. 823.

27 Kada se radi o donatorstvu, po pravilu, takvih ograničenja nema. O tome: Buy, F. i dr., nav. delo, str. 827.

28 Ove klauzule ne mogu da proizvedu pravno dejstvo ako imaju za cilj ograničavanje konkurencije tako što se određuje da sponzor ima isključivo pravo pristupa nacionalnom takmičenju. O tome: Buy, F. i dr., nav. delo, str. 830 .

29 O tome: Monnerville, F., nav. članak, str. 91.

30 Simon, G. i dr., nav. delo, str. 382; Buy, F. i dr., nav. delo, str. 829. 
Međunarodne trgovinske komore). ${ }^{31}$ Ukoliko sponzorisani prekrši navedena pravila, on će odgovarati za štetu ako tokom izvršenja ugovora zaključi ugovor sa konkurentskom kompanijom. Takođe, smatraće se da je prekršio obavezu postupanja sa dužnom pažnjom i snosiće posledice ako ne obavesti sponzora da pored osnovne sportske aktivnosti obavlja i dodatne povodom kojih je preuzeo obavezu nošenja oznaka drugih sponzora. ${ }^{32}$

Na osnovu zaključenog ugovora sponzor ima obavezu da sponzorisanom pruži materijalnu podršku, koja može da bude novčane ili nenovčane prirode (na primer, kada sponzor preuzima obavezu da finansira realizaciju nekog sportskog događaja), s tim što se može učiniti u oba oblika. Po pravilu, naknada ima novčani oblik u slučaju kada se radi o sponzoru koji ne proizvodi ili ne trguje sa proizvodima koji su potrebni za obavljanje sportske aktivnosti. Kada se radi o novčanom iznosu, on obuhvata fiksni (po pravilu se isplaćuje u ratama) i varijabilni deo, koji obuhvata premije koje plaća sponzor, a čiji iznos zavisi od ostvarenih sportskih rezultata. ${ }^{33}$

Što se tiče sponzorisanog, on treba da ispunjava obaveze na sportskom (ako ima status organizatora takmičenja, on se obavezuje da se događaj realizuje u određeno vreme, sa pravom na određena odstupanja, shodno ugovorenim uslovima; ako nije organizator, obavezuje se da učestvuje na sportskim takmičenjima, kao i da preduzme sve što je potrebno u cilju postizanja što boljih rezultata), kao i na vansportskom planu (da nosi oznake sponzora tokom i nakon takmičenja, za vreme treninga i odnosa sa javnošću, kao što su konferencije za štampu, televizijske emisije, inervjui, skupovi humanitarnog karaktera), ${ }^{34}$ shodno onome što je ugovoreno, ${ }^{35}$ u funkciji prikazivanja i promocije sponzora. ${ }^{36}$ Kada je ugovoreno, sponzorisani može da bude dužan (radi se o obligaciji sredstva) da sarađuje sa sponzorom, tako što će da mu daje savete u pogledu upotrebe određenih materijala ili planirane gradnje.

\section{TIPOVI I SPONZORSKE FORME}

U zavisnosti od oblika podrške, koju sponzor pruža sponzorisanom, razlikuju se finansijsko, materijalno i uslužno sponzorstvo. U slučaju: finansijskog sponzorstva, sponzor plaća sponzorisanom određenu svotu novca, na način i u iznosu koji je

31 Videti: https://www.arpp.org/wp-content/uploads/2016/05/code_consolide_pratique_publicite_ marketing.pdf.

32 Dupaquier, R., Quelques aspects du contrat de sponsoring, https://blogavocat.fr/space/cap-tout$\mathrm{droit/}$ content /quelques-aspects-du-contrat-de-sponsoring_41a76346-426e-46f3-816e-ecf2dd36df0d.

33 Simon, G. i dr., nav. delo, str. 378.

34 O tome: Monnerville, F., nav. članak, str. 90.

35 Prema stavu sudske prakse ugovor o sponzorstvu, sa ograničenim rokom trajanja, s obzirom na njegovu posebnu prirodu, može da se raskine i u slučaju delimičnog neizvršenja obaveza od strane sponzorisanog uz povraćaj celokupnog iznsa koji je primio od sponzora. O tome: Dupaquier, R., nav. članak, https://blogavocat.fr/space/cap-tout-droit/ content /quelques-aspects-du-contrat-desponsoring_41a76346-426e-46f3-816e-ecf2dd36df0d.

36 O tome: Buy, F. i dr., nav. delo, str. 824. Simon, G. i dr., nav. delo, str. 378. 
određen ugovorom; ${ }^{37}$ materijalnog, sponzor snabdeva sponzorisanog sa materijalima potrebnim za odvijanje sportskih aktivnosti; uslužnog, sponzor, umesto da nešto daje ili plaća, pruža sponzorisanom određene usluge (štamparske ili usluge održavanja zelenih površina).

Sve sponzorske aktivnosti, u zavisnosti od toga ko se pojavljuje u ulozi sponzora i ko (ili šta) se sponzoriše, mogu da se posmatraju sa dva aspekta, kao pravni i operacionalni oblici.

Povodom pravnog oblika razlikuje se direktna i indirektna forma sponzorstva. U slučaju direktnog sponzorstva sponzor neposredno zaključuje ugovor sa sponzorisanim. Kada se radi o indirektnom (institucionalnom) sponzorstvu (po pravilu se sponzoriše ekipa ili neka sportska manifestacija, a ne pojedinac), zbog potrebe da se angažuju značajnija sredstva, formira se zaseban entitet u formi društva, asocijacije ili fondacije, preko koga se realizuju sponzorske aktivnosti. Na ovaj način se odvaja sponzorstvo od osnovne delatnosti kojom se bavi sponzor i formira posebna ekipa koja se profesionalno bavi sponzorskim aktivnostima.

Sponzorstvo može da se operacionalizuje pružanjem podrške određenom sportisti (od koga se zauzvrat stiče pravo korišćenja njegovog imidža, uz obavezu sportiste da promoviše njegovo ime, znak, proizvod ili aktivnosti) ili sportskoj ekipi (u ovom slučaju se stiče pravo korišćenja imidža ekipe, s tim što se kao neposredni izvršioci onoga što je ugovoreno pojavljuju lica koja vode ekipu i sportisti). Osim toga, predmet sponzorisanja može da bude neko postojeće takmičenje, takmičenje koje se održava pod imenom sponzora (na primer, Trofej Lankom, Evijan master), stadion ili sportski kompleks, koji nose naziv neke robne marke ili društva (Etihad - stadion Mančester sitija, Ribok - stadion Boltona, Emirati -stadion Arsenala, Alijans arena - Bajern Minhen, Red Bul arena - Lajpcig, Folksvagen arena Volsburg). Ovaj oblik sponzorstva je naročito raširen u SAD gde $70 \%$ stadiona profesionalnih košarkaških, fudbalskih, hokejaških i bejzbolskih klubova imaju ime sponzora, odnosno njegove marke. Sponzorstvo preko imenovanja postaje sve prisutnije, jer omogućuje sponzoru da ostvari najveći stepen vidljivosti i prisutnosti u javnosti. Ova forma sponzorstva, za razliku od sponzorstva „majce“, ne vezuje se za sportske rezultate, a u okviru sportskog kompleksa mogu da se održavaju različita takmičenja i korisnici mogu da budu različita lica. Po pravilu se ovakvi ugovori zaključuju na duži rok, u trajanju od 10 do 30 godina. ${ }^{38}$

37 Najveću sponzorsku svotu (147 miliona evra za 15 godina) platili su Emirati Arsenalu kako bi dobili pravo da se stadion nazove Emirati stadion. O tome: Dubé Kimberley, D., nav. delo, https:// ecole-de-commerce-de-lyon.fr/wp-content/ uploads / 2015/07/M\%C3\%A9moire-Marketing-KimberleyD-M1-.pdf, str. 12.

38 O oblicima sponzorstva: Les contrats de sponsoring sportif, http://excerpts.numilog.com/books/ 9782359711172.pdf, str. 13-19. 


\section{OGRANIČENJA U POGLEDU MOGUĆNOSTI ZASNIVANJA I REALIZACIJE SPONZORSTVA}

U osnovi postoje četiri grupe pravila kojima se postavljaju graničnici za uspostavljanje i realizaciju sponzorskog odnosa. To su: 1) pravila kojima se štite osnovna ljudska prava i integritet sponzorisanog (sponzora); 2) pravila kojima se određuju granice u pogledu isticanja oznaka i načina prikazivanja sponzora; 3) pravila kojima se ograničava mogućnost sportistima da komercijalizuju sopstveni imidž, odnosno zabranjuje ili ograničava nosiocima pojedinih aktivnosti da steknu status lica koja sponzorišu sport; 4) pravila kojima se štiti konkurencija na tržištu.

1) Sponzori često nastoje da kontrolišu ponašanje sportista kako bi sprečili štetne posledice po sopstveni imidž, koje mogu nastati kao rezultat izgovorenih reči ili preduzetih postupaka od strane sportista. To se čini unošenjem u ugovor klauzule o očekivanom ili zabranjenom ponašanju. U načelu, takve ih klauzule obavezuju da se uzdrže od bilo kakvih komentara ili ponašanja koja bi mogla nepovoljno da utiču na reputaciju sponzora. Valjanost takvih klauzula treba procenjivati sa velikom dozom opreznosti, jer se njima može ugroziti sloboda izražavanja i pravo na poštovanje privatnog života. Tako, na takve klauzule se sponzori ne mogu pozivati i one ne mogu da proizvedu nikakve štetne posledice za nosioce sportskih aktivnosti ako se, na primer, iznese osnovan stav da isporučena oprema nije odgovarajućeg kvaliteta. Ali, ako se sportista dopinguje, takvo ponašanje može da proizvede štetne posledice za njega i sponzor može da se pozove na takvu klauzulu. ${ }^{39} \mathrm{U}$ svakom slučaju prilikom procene takvih klauzula treba uzeti u obzir odnos u kome se nalazi predmet ugovora i opravdana očekivanja sponzora. ${ }^{40}$

U vezi sa zaštitom integriteta sponzorisanog, u Zakonu o oglašavanju je određeno da sponzor ne može ograničavati kreativnu slobodu sponzorisanog lica, njegova prava na samostalno upravljanje, određivanje cilja i sadržaja sponzorisane aktivnosti. On ne može sponzorisanjem ugroziti integritet sportskog sadržaja sponzorisane aktivnosti i ne može da naškodi ugledu sponzorisanog lica. I, obrnuto, sponzorisano lice sponzorisanom aktivnošću ne može menjati naziv, odnosno ime sponzora, njegov robni ili uslužni žig, niti može na drugi način da ugrozi ugled ili imidž sponzora (čl. 66) ${ }^{41}$

39 Činjenica da je prema sportisti pokrenut postupak antidoping kontrole ne može da posluži kao osnov za raskid ugovora. O tome: Simon, G. i dr., nav. delo, str. 380.

40 Simon, G. i dr., nav. delo, str. 379.

41 Navedena pravila predstavljaju prepev preporuka koje su sadržane u Kodeksu o oglašavanju i komercijalnoj komunikaciji Međunarodne trgovinske komore u Parizu (2011), kojima je, između ostalog, definisan princip autonomije (sponzor mora da poštuje autonomiju sponzorisane osobe u obavljanju njegovih aktivnosti, a za uzvrat sponzorisani mora da ispunjava ciljeve koji su definisani ugovorom o spozorstvu) i poštovanja predmeta sponzorstva (sponzori moraju da poštuju sportsku sadržinu ili stvari pod sponzorstvom, da izbegavaju da zloupotrebljavaju svoj položaj tako što bi škodili ugledu, dostojanstvu ili imovini sponzorisane osobe, i obrnuto, sponzorisani ne sme da ugrozi komercijalni renome sponzora) (čl. B2 i B5). Videti: https://www.arpp.org/wp-content/uploads/2016/05/code_consolide_pratique_publicite_ marketing.pdf. 
2) Sponzorski odnos je omeđen pravilima koja donose sportski savezi. Tim pravilima se često određuju uslovi pod kojima se može realizovati neko takmičenje, uz pretnju izricanja strogih disciplinskih mera u slučaju njihovog kršenja. U vezi sa tim određuje se broj (francuska atletska i teniska federacija određuju da se na opremi može nositi oznaka samo jednog sponzora), mesto i veličina oznaka, koje se mogu naći na opremi sportista, radi očuvanja identiteta igrača na terenu, očuvanja igre i izbegavanja moguće konfuzije. Zbog otklanjanja rizika u vožnji auto-moto savezi zabranjuju korišćenje i pričvršćivanje na zastakljenim površinama luminescentnih napomena. Osim pravila kojima se određuju uslovi za nošenje oznaka, postoje i ona kojima se propisuje način oglašavanja u prostoru, kao što je slučaj sa teniskim savezom (kako bi se predupredio nepovoljan uticaj na koncentraciju sportista, reklamni panoi mogu da budu samo u zelenoj i crnoj boji). ${ }^{42}$

3) Prema važećem pravilu iz Zakona o sportu (čl. 128), vrhunski sportisti ne mogu da steknu status sponzorisanog, i tako komercijalizuju vlastiti imidž, ako su stekli pravo na novčanu pomoć, odnosno izgubiće novčanu pomoć ako steknu status sponzorisanog. Ovim pravilom se neosnovano dovode u odnos međusobne isključivosti dva različita interesa (time se indirektno ograničavaju načini sticanja sredstava, a na osnovu postignutih rezultata) : opšti interes da se na određeni način finansira sportista, koji ima određeni status i koji je ispunio potrebne uslove za dobijanje novčane pomoći, i individualni interes sportiste da slobodno raspolaže imidžom koji je stekao bavljenjem sportom.

Shodno raširenom stavu da nosioci određenih aktivnosti, zbog potencijalne opasnosti da negativno utiču na mlade, nisu podobni da budu sportski finansijeri, ${ }^{43}$ u Zakonu o oglašavanju određene su tri kategorije lica u vezi sa kojima postoje ograničenja u pogledu sponzorisanja. Prvo, oglašivač alkoholnih pića (čl. 67), ne može da sponzoriše sportiste, sportske klubove, sportska takmičenja, uključujući i sponzorisanje pojedinaca, odnosno učesnika tih manifestacija. Ova zabrana se ne odnosi na oglašivača alkoholnih pića sa sadržajem alkohola manjim od $20 \%$. Drugo, priređivač klasičnih i posebnih igara na sreću ne može da sponzoriše decu ili maloletnike, njihove aktivnosti, kao ni lica ili aktivnosti čiju publiku pretežno čine deca ili maloletnici (čl. 68). Treće, oglašivač duvanskih proizvoda ne može da sponzoriše sportiste, sportske klubove, sportska takmičenja, uključujući i sponzorisanje pojedinaca, odnosno učesnika tih manifestacija. Ovom zabranom su obuhvaćeni i proizvođači elektronskih cigareta (čl. 69).

4) Pravila o zaštiti konkurencije mogu da se pojave kao osnov kojim se ograničava (sprečava) odvijanje sponzorskih aktivnosti. ${ }^{44}$ Do toga će doći ako se zbog načina na koji je zaključen ugovor o sponzorstvu (ima prirodu tzv. restriktivnog sporazuma) narušava slobodna utakmica na tržištu, odnosno nastaje poremećaj u odvijanju

42 O tome: Monnerville, F., nav. članak, str. 91.

43 Isto, str. 380.

44 U sferi sporta sporazumi kojima se ograničava konkurencija najčešće se zaključuju povodom marketinga sportskih događaja, organizacije takmičenja i sponzorstva. O tome: Berthault, F., Le droit de la concurrence appliqué au secteur sportif, Legicom, br. 2000/23, str. 52. 
sportskih aktivnosti. Kada se radi o sportskom sponzorstvu, antikonkurentski karakter mogu da imaju sporazumi koji se zaključuju između sportske federacije ili profesionalne lige, $\mathrm{s}$ jedne strane, i sponzora, s druge strane (sporazumi između sponzora i sportiste ili sportskog kluba nemaju za posledicu povredu konkurencije). Kako bi se izbegao takav karakter potrebno je da federacija (liga) omogući svim zainteresovanim licima, na osnovu javnog poziva, da steknu poziciju druge ugovorne strane, pri čemu ugovor može da se zaključi najviše na četiri godine, bez klauzule o odricanju od prava na raskid ugovora i pravo sponzora na prećutno produženje važenja ugovora. ${ }^{45}$

U slučaju zaključenja ugovora o sponzorstvu između kluba i sponzora postoji mogućnost da se dovede u pitanje regularnost takmičenja ukoliko isto lice sponzoriše više klubova koji učestvuju u istom takmičenju. Jer, sponzor može da ima interes da jedna od ekipa, suprotno takmičarskim principima, bude u povlašćenom položaju u odnosu na drugu. Ovakve situacije se mogu rešiti tako što bi se u sportske zakone uključila pravila o prevenciji sukoba interesa zabranom višestrukog sponzorstva. Međutim, u vezi sa tim treba razmisliti koji bi to stepen ograničenja višestrukog sponzorstva bio opravdan, a da to nema za posledicu gašenje ovog oblika finansiranja sporta. $^{46}$

\section{ZAKLJUČAK}

Sportsko sponzorstvo se pojavilo sredinom XIX veka, a krajem XX veka je postalo najznačajniji način finansiranja profesionalnog sporta. Zbog obostrane mogućnosti da na najbolji način zadovolje svoje interese, i sponzor i sponzorisani, sponzorska podrška sportu iz godine u godinu raste. Međutim, materijalni rast sponzorskih ulaganja nije propraćen odgovarajućom regulativom. Još uvek ugovor o sponzorstvu spada u kategoriju neimenovanih ugovora, što znači da nisu definisana pravila kojima bi bio regulisan ovaj ugovor, a nema ili su retka pravila o sportskom sponzorstvu. Zakon o sportu Republike Srbije prepoznaje sponzorstvo, kao mogući izvor sticanja sredstava (što je dobro), ali i ograničava mogućnost uspostavljanja odnosa sponzorstva u odnosu na vrhunske sportiste, zbog čega se može postaviti pitanje opravdanosti i zakonitosti takvog pravila kojim se ograničava pravo sportista da komercijalizuju vlastiti imidž, a da pri tom ne gube prava koja im pripadaju po osnovu statusa vrhunskog sportiste.

Ono što odvaja ugovor o sponzorstvu od drugih ugovora je činjenica da je u osnovi podrška koju pruža sponzor (finansijska ili materijalna ili i jedna i druga) ekvivalentna (obuhvata) vrednosti robe na kojoj stiče pravo korišćenja, a to je imidž sponzorisanog, i vrednosti usluga koje shodno zaključenom ugovoru pruža sponzorisani. Posebnost sponzorsta, vezano za pravo korišćenja imidža

45 Isto, str. 53.

46 Simon, G. i dr., nav. delo, str. 374. 
sponzorisanog, otvara pitanje odnosa i raspodele prava korišćenja kolektivnog i individualnog imidža, što je nužno da se uredi posebnim pravilima.

\section{SPORTS FINANCE AND SPONSORSHIP}

Sponsorship, especially when it comes to professional sports, has a special significance for financing this kind of sporting activities. Namely, sponsorship is in the function of efficient satisfaction of sponsor's interests, which is reflected in maximization of his presence and public recognition through the interconnection with the carrier of some sporting content. At the same time, thanks to sponsorship, sponsored party acquire the ability to achieve better and more prestigious results than others. Since sponsorship has its own specificities, which clearly distinguish it from other contractual relationships, author pointed out: the concept of sports sponsorship; the importance of the sponsored party's image and the right to use the image, which the sponsor acquires upon conclusion of the contract; the relationship between individual and collective image; limitations for establishing and implementing sponsorship.

Key words: sport, contract, sponsorship, sponsor, image, relationship. 